\title{
O “Diário de Notícias" de Ribeirão Preto nos anos de 1960: Religião e Política
}

\author{
Maximiliano Martin Vicente ${ }^{1}$ \\ Nayara Kobori2
}

\section{Resumo}

O presente artigo tem como objetivo a nalisar o jomalismo praticado no interior do estado de São Paulo nos anos de 1960, tendo recorte o impresso Diário de Notícias (DN), de Ribeirão Preto. O matutino era dirigido pela Arquidiocese da Igreja Católic a do município, o que nos faz refletir sobre os encadeamentos entre o jomalismo do interior e Religião, e qual foi o comportamento desse segmento e do município nos anos de autoritarismo brasileiro, em um contexto regional. A análise parte da observação crítica do jomal, como foma de compreender o posicionamento político e ideológico do DN, por meio da Hemenêutica em Profundidade. Dessa forma, poderemos inferir sobre a atuação do periódico na sociedade ribeirão-pretana e, como o jomalismo é um instrumento referencial para construir novas representações da realidade e da história regional.

Palavras-chave: J omalismo. Igreja. Interior. Ribeirão Preto.

\section{Abstract}

This article aims to elaborate about the journalism practiced in the state of São Paulo, in 1960s, having as object the printed "Diário de Notícias" (DN), in Ribeirão Preto. The moming was coordinated by the Archdiocese of the Catholic Church in the city, which makes us reflect on the linkages between regional joumalism and Religion, and what was the behavior of this segment and the city in the years of Brazilian authoritarianism, in a regional context. The analysis begins with a critical

1 Graduação em História pela Universidade do Sagrado Coração (1982), mestrado em História pela Universida de Estadual Paulista Júlio de Mesquita Filho (1987) e doutorado em História Social pela Universidade de São Paulo (1996). Livre-docente em História do Brasil em 2008. Atualmente é professor da Universida de Esta dual Paulista Júlio de Mesquita Filho. Atua no programa de Pós-Graduação em Comunicação Midiática da UNESP - Campus de Bauru onde orienta pesquisas na área de Gêneros e Formatos da Comunicação Midiática e leciona a disciplina Comunic ação e História na Nova Ordem Intema ciona I.

2 Mestre em Comunicação Midiática, pela Faculdade de Arquitetura, Artes e Comunicação (FAAC), da UNESP-Bauru. Graduada em Comunicação Social - J o malismo, pela FAAC/UNESP. Tem experiência com pesquisas na área de Comunica ção, J omalismo do Interior, J omalismo de Opinião e História da Imprensa. 
observation of the newspaper as a way to understand the political and ideological positioning of DN through the Hermeneutics in Depth. Thus, we can infer the joumal's role in the society and how joumalism is a reference tool for build ing new representations of reality and regional history.

Keywords: J oumalism. Church. Regional. Ribeirão Preto.

\section{Introdução}

Relacionar história e jornalismo implica em adotar um posicionamento multidisciplinar entendido como uma tentativa de estabelecer relações e inter-relações nas práticas sociais, de maneira a superar as interpretações monolíticas, fragmentadas e parceladas nos processos de produção e socialização do conhecimento. Tal forma de entender o pensamento é representada pela ideia de complexidade, nos moldes propostos por Edgar Morin (2005), e que teria como grande finalidade resgatar o caráter de totalidade do conhecimento e aceitar que os conceitos e as teorias estão conectados entre si.

Embora seja aceita e amplamente utilizada na atualidade, a multidisciplinaridade convive, ainda, com problemas difíceis de serem solucionados. Sem dúvida o principal reside em como compatibilizar e conseguir que duas, ou mais epistemologias, dialoguem e permitam ampliar as interpretações sobre um determinado campo do saber. Uma possível saída para esse dilema consiste em aproximar áreas de conhecimento de tal forma que resulte mais fácil permitir que cada especialista transcenda sua própria particularidade e acolha, de maneira mais efetiva, os saberes de outras disciplinas. Assim, dialeticamente, todos ganham e ampliam as interpretações correspondendo, dessa maneira, para a finalidade da multidisciplinaridade.

Duas áreas bem próximas onde pode ser conseguido esse diálogo são o jornalismo e a história. Tanto o jornalismo, quanto a história coincidem na sua finalidade, ou seja, na compreensão e na decodificação da formação da sociabilidade (VICENTE, 2009). Ambos saberes aceitam que o acontecimento deriva do fato entendido como o episódio desencadeador de mudanças no status quo da sociedade. Para o fato ter destaque deve se encaixar dentro de um processo social no qual se atribui, ou não, relevância por interferir nas relações sociais. O acontecimento existe em função do relato feito dele e justamente na construção desse relato, o jornalismo e a história se encontram, pois, criam versões desde suas especificidades que nos levam a discutir a forma como a 
sociedade se estrutura e age na hora de interpretar e validar determinados acontecimentos.

Entretanto, não ignoramos que existem ruídos quando se estabelece o diálogo entre jornalistas e historiadores. Os historiadores alimentam a ideia da superficialidade realizada pelos jornalistas nas suas análises. Eles apresentariam os fatos de maneira rápida, descontextualizada, sem reflexão ou criticidade. Já os jornalistas se sentem incomodados com a falta de atualização e preocupação dos historiadores com os episódios recentes. O passado seria o campo preferencial no qual a história procura encontrar seu sentido e fundamentar suas afirmações. Assim, ao excluir o presente do seu campo de atuação, a história teria pouca utilidade para o jornalismo mais voltado para a atualidade.

De imediato surge uma questão: trata-se, apenas, de diferenças cronológicas, de concepções teóricas ou de desconhecimento mútuo? Numa passagem extremadamente feliz, Le Goff (1999, p.93) tece considerações relevantes para compreender, como ele mesmo diz, o passado pelo presente e o presente pelo passado, ou seja, a possibilidade do diálogo entre jornalismo e história. Esse historiador, conhecido pelas suas obras relacionadas com a Idade Média, coloca uma pergunta-chave para abordar os acontecimentos dentro da ótica apontada anteriormente: houve na Idade Média fenômenos históricos que esclareçam o presente imediato? O que se passa hoje nos permite compreender melhor o que aconteceu na Idade Média?

Tomando como referência a Guerra do Golfo (2 de agosto de 1990 a 28 de fevereiro de 1991), Le Goff entende que o fato se insere numa problemática de longa duração, na qual árabes e cristãos protagonizaram confrontos, debates e situações marcantes. Dessa maneira, ele vê nas Cruzadas um referencial para iniciar a compreensão do acontecimento mais imediato, ou seja, a guerra mais próxima. Jornalistas e historiadores intercambiando seus conhecimentos e saberes construiriam explicações, de acordo com Le Goff (1999), mais fundamentadas e profundas que fugiriam do simplismo ou do estudo descontextualizado do passado sem ter uma referência com o presente.

Ainda, continuando com sua problematização, o autor alerta para o cuidado com as fontes de informação empregadas nesse construto histórico, tanto com as dos jornalistas, quanto com as dos historiadores. Defende a adoção de algumas preocupações como: uma leitura do presente, do acontecimento, com uma profundidade 
histórica ampla o suficiente para conseguir construir uma opinião fundamentada; aplicar um método crítico em relação às fontes, respeitando suas especificidades; procurar fugir da simples narrativa descritiva, oferecendo explicações interpretativas; e tentar hierarquizar alguns fatos, procurando saber distinguir o que é fato de acidente, pois assim será possível relacionar esse evento com o passado já interpretado e avaliado pelos jornalistas e historiadores. Poucas dúvidas existem na aceitação, portanto, do reconhecimento da importância do jornalismo e da história na construção da realidade social. Ao incidir sobre a formulação do cotidiano, já que sua função principal se centraliza na divulgação dos fatos por eles veiculados, acabam servindo de referência para que as pessoas formem ou rejeitem opiniões e versões solidamente fundamentadas.

Mas é importante que, tanto os jornalistas como os historiadores, tenham claro que elaboram uma reconstituição parcial dos acontecimentos, na qual se procura atribuir um significado e um sentido para o fato descrito. Assim, ambos se distanciam dos relatos baseados na ficção por trabalharem com preocupações e procedimentos que interferem e repercutem no âmbito social. Borrat (FONTCUBERTA \& BORRAT, 2006, p.330) cita alguns procedimentos nos quais jornalistas e historiadores procedem de maneira semelhante. $\mathrm{Na}$ construção da narrativa, ambos descrevem os eventos partindo de rupturas temporais; inserem os personagens num contexto, não devem personalizar os acontecimentos; contextualizam os fatos; ampliam o cenário para dar força ao tema tratado elaborando uma sequência temporal; traduzem para o público a trama estudada sem tentar influenciar com suas opiniões; sua narrativa sempre é provisória, pois, à medida que novos fatos aparecem, o sentido atribuído tem que ser revisto; e, finalmente, jornalistas e historiadores almejam chegar a uma representação mais fiel da verdade.

A narrativa, portanto, parecer ser um dos pontos onde jornalismo e história convergem na elaboração e produção de sentido. A história, mais especificamente, observa e explica como os discursos sociais dominam as dimensões do tempo no qual aconteceram os fatos, garantindo, assim, a construção de relações elaboradoras de práticas sociais específicas a cada momento. Esses discursos são formas de intervenção mediante as quais o historiador ordena o tempo, descreve as redes sociais e cunha uma lógica portadora de sentido específico. A criação da narrativa histórica é o momento no qual o historiador, na condição de pessoa responsável pela elaboração dessa interpretação, determina as classificações, a posição dos fatos, dos homens, das ideias e 
onde e quando se consolidam as justificativas que ele considera convenientes para criar sua versão.

De alguma maneira, esses procedimentos podem ser observados na narrativa jornalística. Ela ocorre também em contextos peculiares e específicos, e usa recursos, normalmente mais amparados nas estratégias narrativas do texto, destinados a cativar seus receptores. A organização narrativa do discurso midiático não é aleatória, portanto realiza-se numa conjuntura claramente determinada e procura originar determinados efeitos bem específicos. No discurso jornalístico, os jornalistas se servem de estratégias textuais que interferem na organização do texto, pois utilizam códigos, articulações sintáticas e pragmáticas, além de outros recursos da linguagem, que levam a uma interpretação por parte do destinatário ou receptor.

Pelo exposto até agora, podemos afirmar que as semelhanças e convergências entre o jornalismo e a história se encontram na repercussão social que os fatos podem ter. Partimos do pressuposto de que nessa aproximação prevalece a procura de um ideal para o jornalista e para o historiador. O jornalista tem como missão principal esforçar-se para reconstituir e explicar ao seu leitor a sequência e os laços que se vinculam às notícias apresentadas cotidianamente. Dessa maneira, a informação adquire um sentido mesmo que ela seja desmontada no dia seguinte pela revelação imposta por outros acontecimentos. Já o historiador realiza processo semelhante na medida em que tenta reconstituir por que caminhos o fato chegou ao presente. O historiador, nessa evolução, analisa as estruturas que ocasionaram tal desfecho com relação ao tema que estuda.

\section{Aproximações entre História e Jornalismo Regional}

Uma das maneiras mais interessantes de observar como se opera a aproximação do jornalismo com a história ocorre quando se estudam fatos e acontecimentos locais ou regionais, ou seja, quando se reduz a escala de observação dos acontecimentos. Em termos de historiografia essa redução ficou conhecida como micro história e merece ser explicada para evitar simplismos relacionados com os acontecimentos que estuda, muitas vezes tido como irrelevantes por estarem veiculados ao cotidiano local. Para Barros (2011) delimitar o espaço a um determinado local nos permite examinar com mais profundidade as relações sociais que se estabelecem nele. Para ele a micro história deve procurar caracterizar a peculiaridade que um acontecimento adquire dentro de um recorte espaço-temporal que o historiador faz. 
Quando um historiador analisa uma pequena comunidade não aborda, especificamente, a pequena comunidade, mas estuda como os acontecimentos macros se processaram no âmbito daquela região. Em razão disso o objeto de estudo, mesmo sendo localizado, ajuda na compreensão dentro de uma prática social especifica "a trajetória de determinados atores sociais, um núcleo de representações, uma ocorrência ou qualquer outro aspecto que o historiador considere revelador em relação aos problemas sociais ou culturais que está disposto a examinar" (BARROS, 2011, p. 164). Assim, se pode afirmar que a micro história lida com o fragmento como um meio para enxergar uma questão social mais ampla.

Dentro do jornalismo, o equivalente à micro história pode ser encontrado no jornalismo local, também conhecido como regional ou de proximidade. Apesar dos múltiplos termos, todos eles compartilham de uma mesma essência, traduzida pelo professor e pesquisador português, Carlos Camponez, como a presença de uma forte"territorialização dos seus públicos, a proximidade face aos agentes e instituições sociais que dominam esse espaço, o conhecimento dos seus leitores e das temáticas correntes na opinião pública local"(CAMPONEZ, 2002, p. 19).Portanto, a imprensa local e regional centra-se no compromisso com o seu território geograficamente localizado, e com as pessoas que ali habitam. Dirceu Fernando Lopes (1998) complementa o raciocínio afirmando que o morador buscará e encontrará nos diários locais as informações que interessam para o seu dia-a-dia. Esse mesmo leitor também busca as ocorrências em nível nacional e internacional, mas ele necessita de um órgão que reflita seus costumes e seus ideais, criando laços de identidade (BELTRÃO, 2013).

Essa forma de realizar o jornalismo tem muitas semelhanças com a denominada micro história. A proximidade com o público, o espaço disponibilizado para abordar questões locais e regionais e o papel de fiscalizador da coisa pública atribuem ao jornal local relevância suficiente para ser objeto de estudo científico tão importante quanto o jornalismo de massas (COLUSSI, 2005). Independentemente de sua linha editorial, o periódico local pode informar o que interessa mais de perto a seus leitores garantindo, assim, um processo natural de identificação do leitor com o jornal local (LOPES, 1998). Por estar próximo do cidadão, torna-se um meio facilitador de cidadania uma vez que, ao tratar de temas diretamente relacionados com o público, permite que a população participe do desenvolvimento local, lute pelos seus direitos e fiscalize o poder público. Isso não significa colocar o jornalismo local no pedestal, mas sim, destacar o fato de que 
convive (de perto) com os problemas da comunidade e que se assemelha muito ao modus operandi da micro história, em seus objetivos, finalidades e forma de apurar e agir no âmbito de uma sociedade geograficamente delimitada. O papel da imprensa local é tornar público as decisões, as reivindicações e os fatos locais e regionais. Isso leva o jornal do interior a ser a principal fonte de informação, transformando-o no melhor ponto de encontro entre quem quer vender ideias e quem quer comprar ideias. Nada substitui a visão local e, portanto, as possibilidades de diálogo com a micro história são mais do que factíveis.

Ao mesmo tempo o jornal local apresenta visões do contexto macro, algo que a história regional, também, não pode esquecer. Problemas relativos ao país, ou mesmo ao publicar notícias de acontecimentos internacionais são elementos encontrados frequentemente nas páginas das folhas regionais. Contudo, não podemos ignorar que o jornal local ainda carrega algumas características estereotipadas no passado. Para alguns, ele ainda é conhecido como uma imprensa "artesanal", mais opinativa que informativa, que interfere parcialmente nos bastidores da política e que convive com precariedades técnicas.

Precisamente nessa tensão entre o local e o nacional, entre o público e o privado que se deve adotar um ponto de vista crítico para não ser iludido nas informações obtidas e publicadas no meio impresso. Nos saberes das duas áreas podemos encontrar subsídios para tentar mitigar esses possíveis elementos de manipulação presentes tanto na micro história como no jornalismo local. Thompson (2009) oferece pistas para fugir dessas forças de manipulação. Nesse sentido ele alerta para que sempre os dados analisados, seja pelo jornalismo ou pela micro história, devam ser vistos como formas simbólicas que, em determinados contextos, servem para estabelecer (produzir, criar, instituir e sustentar, manter e reproduzir) sistematicamente desigualdades sociais, entendidas como relações de poder ou de dominação.

Thompson defende a ideia de que as abordagens dos fatos devam se assentar num tripé: análise sócio histórica, análise formal ou discursiva e a interpretação/reinterpretação, o que denomina de Hermenêutica de Profundidade (HP). A primeira centra-se nas "condições sociais e históricas da produção, circulação e recepção das formas simbólicas" (THOMPSON, 2009, p. 34). Com isso, o contexto e suas influências sociais, políticas, econômicas, culturais e históricas são o fundamento da análise discursiva, com suas características estruturais, padrões e relações. 
(THOMPSON, 2009, p.369). A interpretação/reinterpretação implica em um movimento de síntese, por uma construção criativa de possíveis significados. (THOMPSON, 2009, p. 375).

Esse procedimento não isenta que se cometam erros, mas sem dúvida numa contextualização solidamente fundamentada, num ambiente de longa duração, como defendia Le Goff, se estabelece uma linha de interpretação onde se explicitam as relações de dominação. Assim, contextualizado o fato torna-se mais difícil de ser manipulado, seja por jornalistas, seja por historiadores, seja analisando a micro história e o jornalismo local, seja abordando fenômenos de caráter nacional ou global. A singularidade e a originalidade de uma obra histórica ou de uma notícia publicada num determinado jornal, estão justamente na articulação estabelecida pelo autor entre todos os elementos de sua narrativa, o que inclui o conteúdo, o tipo de explicação dos fatos, os pressupostos éticoideológicos, bem como o gênero do enredo. Ou seja, a aproximação da história com o jornalismo cria um campo de reflexão e convergência que de forma alguma são excludentes, ambos se complementam e quando utilizados em conjunto contribuem para o que Morim (2005) denominava de complexidade.

\section{A Política Nacional e Local nos anos de 1960}

Os anos 1960 estiveram marcados por um confronto que desembocaria no regime autoritário de 1964. Talvez por isso, Toledo (1982) afirma que o governo João Goulart nasceu, conviveu e morreu sob o signo do golpe de Estado. Efetivamente, com a renúncia de Jânio Quadros, em 25 de agosto de 1961, assumiu interinamente Ranieri Mazzilli, e já naquele momento os ministros militares, contando com o apoio de dois partidos conservadores, a União Democrática Brasileira (UDN) e o Partido Social Democrático (PSD), tentaram barrar o retorno de Jango ao país, o que acarretaria no parlamentarismo brasileiro. De acordo com Toledo (1982), o alinhamento de Goulart com as denominadas posturas progressistas assustava os setores conservadores, temerosos que implantasse no país um regime próximo aos modelos socialistas. Somente em janeiro de 1963, com um plebiscito, Jango recuperaria o cargo de Presidente.

Já com os dias contados para acabar seu mandato, Goulart promoveu um verdadeiro embate político e ideológico no país, considerado por alguns como o fim do movimento populista (WEFFORT, 1978). Tal embate colocava frente a frente as forças sociais antagônicas. Do lado progressista, se destacava o movimento estudantil e o 
movimento operário e parte da Igreja Católica identificada com a denominada Teologia da Libertação e que atuava junto as camadas populares através dos Movimentos Eclesiais de Base (MEB). Outro movimento de expressão que apoiou a João Goulart foi o realizado pelos camponeses congregados nas Ligas Camponesas, defensoras dos direitos dos trabalhadores rurais e da Reforma Agrária. A conjugação de todos esses movimentos aterrorizava cada vez mais as elites brasileiras, pois mostravam a possibilidade de rompimento do controle das classes dominantes do país. Por outro lado, setores mais conservadores, congregados principalmente em torno da UDN e que contavam com o apoio do Instituto Brasileiro de Ação Democrática (IBAD) e o Instituto de Pesquisa e Investigações Sociais (IPES) criticavam tenazmente as medidas defendidas por Goulart.

Essa situação se alteraria quando João Goulart lança, em 13 de março de 1964, no comício da Central do Brasil, no Rio de Janeiro, as Reformas de Base. Entre as muitas mudanças pretendidas pelo projeto da Reforma de Base se destacava a reforma agraria. As aspirações das reformas pretendidas coincidiam com os anseios da classe média brasileira, dos trabalhadores e dos empresários nacionalistas. Por esse motivo grande parte do povo brasileiro aderiu ao movimento, o que desagradou os setores mais conservadores do Brasil.

A ofensiva golpista não tardou a se manifestar: poucos dias após o Comício onde se apresentaram as Reformas de Base houve "Marcha da Família com Deus pela Liberdade". Nela setores das classes médias, parte do clero e da burguesia, sob a bandeira do anticomunismo e da defesa da propriedade, da fé religiosa e da moral cristã, saíram às ruas nas maiores capitais do país contra o governo Goulart. A real intenção de tais manifestações era criar um clima favorável à intervenção militar, bem como, incitar as Forças Armadas a dar o golpe de Estado. Dessa maneira, deu-se o golpe se concretizou em 31 de março de 1964.

Logo após o golpe ter sido consumado se iniciou uma perseguição violenta contra os setores que tinham se mobilizado na defesa das propostas de Goulart, como a CGT, a União Nacional dos Estudantes, as Ligas Camponesas e grupos da Igreja católica ligados à Teologia da Libertação como a Juventude Universitária Católica e a Ação Popular. Mas não foram todos os que sofreram esses ataques. O golpe foi bem visto e apoiado por setores importantes da imprensa, o empresariado, proprietários rurais, setores conservadores da Igreja Católica e governadores de estados importantes como Carlos Lacerda, da Guanabara, e Magalhães Pinto de Minas Gerais, assim como amplos setores 
da classe média. Iniciava-se um regime político denominado de autoritário, na qual a democracia e a representação ficaram comprometidas enquanto o Estado ampliava sua autoridade e cerceava as liberdades democráticas. Diferentemente de outras ocasiões, agora, em 1964, os militares, além de promover a conquista do Estado, permaneceriam nele até a denominada redemocratização dos anos 1980, ou seja, depois de conservar-se por vinte anos no poder.

Em nível regional, Ribeirão Preto $^{3}$ também enfrentava a dicotomia e embates entre os setores progressistas e conservadores na cidade. No período anterior ao golpe, vigorava a administração municipal de Condeixa Filho, do Partido Social Progressista (PSP), que compartilhava da política de Adhemar de Barros que, na época, vivia um radicalismo de direita (MARINO, 1988). Ao mesmo tempo, entidades estudantis locais, como o Centro Nacionalista Olavo Bilac ${ }^{4}$, estudantes da Universidade de São Paulo (USP), e até entidades organizadas como a Aliança Nacional Libertadora (ALN), já anunciavam a trama golpista nacional e se posicionavam a favor do Presidente Jânio Quadros (PAULINO, 2012).

Com o final da prefeitura de Condeixa Filho, Ribeirão Preto já sentia o clima de cisão ideológica, que colaborava para germinar preconceitos pela esquerda e direita, fato que influenciou na imagem dos candidatos à prefeito, em 1963. Concorreram os políticos: Antônio Carlos Sant'Anna ${ }^{5}$, pelo Partido Socialista Brasileiro (PSB), Orlando Jurca ${ }^{6}$, candidato do Partido Comunista Brasileiro (PCB) e Welson Gasparini ${ }^{7}$, vencedor das eleições pelo Partido Republicano Paulista (PRP). O novo prefeito assumiu o cargo no dia 1 de janeiro de 1964, afirmando seu compromisso com os movimentos da Igreja Católica e da Social Democracia Cristã, ou seja, com uma ala progressista católica, alinhada com a Conferência Nacional dos Bispos do Brasil (CNBB). Gasparini também participava e

\footnotetext{
3 Ribeirão Preto está localizada na porção nordeste do estado de São Paulo, com 666323 habitantes, segundo dados do IBGE/2015. A cidade é conhecida como "capital do a gronegócio" e teve sua economia calcada na exportação cafeeira.

4 O Centro Nacionalista Olavo Bilac é uma organização formada por estudantes da Escola Munic ipal Otoniel Motta.

5 Antônio Carlos Sant'Anna era redator-chefe do jomal "Diário da Manhã". Atuou como jomalista e político, já ocupando cargos de vereador na Câmara Municipal.

6 Orlando J urca já exerceu cargos de verea dor e Presidente na Câmara Municipal.

7 Welson Gasparini era jomalista no DNe locutor na rádio ZYR-79. Chegou a chefiar a administração municipal como Prefeito de Ribeirão Preto, por três mandatos. Atualmente, Welson Gasparini exerce o cargo de Deputado Estadual pelo Partido da Social Democracia Bra sileira (PSDB).
} 
apoiava greves de trabalhadores, fato que foi questionado por outros políticos conservadores da época. Após o golpe, o Prefeito manteve a sua postura, mas acabou filiando-se à ARENA, partido de situação do regime militar, como forma de permanecer no poder. Gasparini manteve-se na Prefeitura até 1969.

Tomado o conhecimento do golpe, a Câmara Municipal fez coro aos militares, e passou a cassar mandatos de políticos considerados "subversivos". O novo regime desarticulou partidos políticos, representantes da oposição e movimentos populares. Paulino (2012) discorre que logo nos primeiros dias de autoritarismo, opositores do regime foram presos, como nacionalistas, comunistas, socialistas, membros filiados a partidos de esquerda e, até mesmo, jornalistas que se mostraram contrários à política militar vigente. Nesse contexto, a imprensa fez-se extremamente presente para divulgar ideias que combatiam as tramas golpistas, e combater a hegemonia das classes conservadoras.

\section{O "Diário de Notícias": Jornalismo do interior e Comunidade}

O surgimento da imprensa na região de Ribeirão Preto está ligado à emergência da cultura cafeeira, no final do século XIX. De início, os jornais eram vistos como palcos políticos, representando interesses de conglomerados dos grandes empresários e barões do café. Em 1950, a modernização da imprensa nos grandes centros urbanos, principalmente no Rio de Janeiro e em São Paulo, modificou os parâmetros do jornalismo brasileiro. A influência norte-americana, a separação de informação e opinião, o uso do lead, da pirâmide invertida e do fotojornalismoforam alguns dos elementos que moldaram a imprensa do país (RIBEIRO, 2007). Araújo \& Geraldo (2006) discorrem que essas mudanças foram incorporadas aos jornais regionais dez anos depois, em 1960. Em Ribeirão Preto, os autores dizem que as novas concepções e a modernização podem ser vistas com clareza nos periódicos "A Cidade", "Diário da Manhã" e o "Diário de Notícias", que investiram em sua reestruturação gráfica e textual.

De forma irônica, ao mesmo tempo em que ocorria a modernização da imprensa regional, era deflagrado o golpe, sufocando a relativa autonomia dos jornais. Entretanto, isso se deu em nível político, não impedindo o desenvolvimento dos veículos da cidade, que sobreviveram ao conturbado momento histórico. O "A Cidade" atravessou intocável todo o período militar, e hoje é líder em circulação na região, sendo comprado pelas Emissoras Pioneiras de Televisão Brasileira (EPTV), filiada da Rede Globo. Já o "Diário da Manhã" e o "Diário de Notícias" acabaram fechando as portas em meados dos anos de 
1980, por corte de anúncios publicitários e falta de assinantes ${ }^{8}$. De acordo com Araújo \& Geraldo (2006), o "A Cidade" possuía um perfil mais conservador, enquanto o "Diário da Manhã" e o "Diário de Notícias" tinham um viés de esquerda.

O DN foi fundado em 1928, pela família Silva Lisboa. Nos anos de 1940, o matutino foi vendido ao professor Oscar de Moura Lacerda, que passou pouco tempo à frente do veículo, vendendo-o para a Cúria Arquidiocesana de Ribeirão Preto, já em 1944. $\mathrm{Na}$ década de 1950, o jornal conseguiu uma tiragem de 8.500 exemplares (SANT'ANNA, 2010). No mesmo período, que o DN passa por modificações gráficas e textuais, incorporando elementos do jornalismo norte-americano, como a separação de informação e opinião (ARAÚJO \& GERALDO, 2006), serviços de telégrafo, parceria com a agência noticiosa internacional ASA-PRESS UNITED, e difundidos princípios da modernidade da época.

O jornal adotava o formato standard (com $50 \times 30 \mathrm{~cm}$, aproximadamente), com número de páginas que variam de 4 a 12 folhas, dependendo da edição. Logo abaixo do título, aparecia o slogan "A César o que é de César e a Deus o que é de Deus - Mt. XXII, 21". Em 1960, era visível a segmentação dos assuntos no DN: a primeira página era reservada à veiculação das notícias da agência internacional, dando destaque para assuntos nacionais e internacionais de grande apelo público e valor noticioso (na grande maioria das vezes, os assuntos políticos eram priorizados). Na segunda página, a coluna editorial "Nosso Comentário" se fazia presente, se portando com o espaço próprio de manifestação do jornal e do corpo de editores. É também na segunda folha que eram veiculadas datas e horários de missas e outros assuntos religiosos católicos da região. A terceira página era reservada para assuntos estritamente locais, demonstrando a preocupação do DN em aproximar-se da comunidade. Também havia presença de anúncios de serviços comerciais e profissionais. A mesma lógica era compartilhada pela quarta página, que traziam além dessas notícias, informações sobre a vida social de nomes conhecidos do município. A quinta página tinha uma aproximação com as notícias do esporte. Dava-se prioridade para os campeonatos regionais e, logo depois, os nacionais. Por fim, a última página era reservada à assuntos locais, também fortalecendo a visão do jornal como um porta-voz de Ribeirão Preto. Encontramos o quadro "situação

\footnotetext{
8 Não há dados sobre o ano exato em que esses dois jomais pararam de circular. Há dados conflituosos na bibliografia consultada. Entretanto, sabe-se que com o endurecimento do regime militar, o número de edições tomava-se cada vez menor, sendo que aospoucos, eles deixaram de existir.
} 
política", com mescla de informações com menos de um parágrafo sobre acontecimentos políticos municipais e nacionais.

Vemos, portanto, uma lógica de construção da notícia no DN. Apesar de trazer a preocupação com as informações internacionais e nacionais, tendo diálogo com agência de notícia internacional, o matutino tem como principal objetivo veicular os assuntos da urbe em que se encontra, como forma de reforçar sua presença na localidade e manter um diálogo constante com a sociedade ribeirão-pretana. É nesse sentido que Dornelles (2005) constrói o argumento de que a filosofia do jornal interiorano tem como pretensão voltar-se para a comunidade (no caso, os moradores da cidade em que o veículo circula) e atender os seus anseios e reivindicações. Tendo em vista essas considerações, as notícias que serão divulgadas vão de acordo com o que o a cidade do interior necessita, formando um jornal do interior que vai na contramão da grande mídia para atender necessidades particulares de cada espaço urbano, mas que ao mesmo tempo, incorpora características dos grandes veículos para criar uma identificação com o público.

Ao criar esse laço com a comunidade a mídia local irá aproximar-se de práticas da mídia comunitária que ajudaram a construir as vertentes do jornalismo do interior. Dornelles diz que isso resulta em "manifestações de comprometimentos sociais de ambas, em maior ou menor grau e na disseminação da diversidade cultural, através da mídia local e comunitária" (DORNELLES, 2005, p.1). No caso do DN, essa aproximação aparece cada vez mais nítida, tendo em vista que a mídia comunitária surge de ações das Comunidades Eclesiais de Base (CEBs) e, há a preocupação do corpo editorial da folha em trazer questionamentos sociais do interior, em conjunto com práticas promovidas pela Igreja Católica de Ribeirão Preto.

Além das notícias, outro modo de identificação das práticas do jornalismo no interior refere-se aos seus profissionais. Diretores e jornalistas do periódico devem participar de atividades promovidas pela sociedade local, buscando soluções e, assim, contribuindo para o progresso da região (DORNELLES, 2005). No caso do DN o diretor, Pe. Celso Ibson Syllos (1961 a 1964), também era líder da "Frente Agrária Paulista", movimento que buscava dialogar com os trabalhadores rurais, promovendo debates e educando-os através do método Paulo Freire.

A preocupação com o setor rural era uma das tônicas no DN. A posição ocupada pelo Pe. Celso, ao lado das medidas reformistas propostas por Goulart em 1963, fomentaram discussões sobre Reforma Agrária em Ribeirão Preto, aproximando cada vez 
mais o jornal da comunidade em questão. No editorial "Libertemos a roça", o diretor da folha tece considerações sobre as Reformas de Base e pede apoio às Prefeituras Municipais:

É necessário dar apoio a esse tipo de iniciativas renovadoras, adotandose uma forte política de reformulação do sistema de posse e exploração de terras. As Prefeituras Municipais estão hoje com enorme chance de liderar esse movimento, já que o imposto territorial rural oferece ensejo a uma total revisão de critérios, encerrando-se proporcionalmente as terras boas não cultivadas e as grandes superfícies?

E continua:

Estamos convencidos de que nosso município de Ribeirão Preto poderá dar magnífico exemplo nessa linha de uma Revisão Agrária corajosa e bem planejada. O primeiro passo consistirá, sem dúvida, em montar uma perfeita máquina arrecadadora e fiscal, depois de se executar oportuna reforma no Código tributário. (...) Além de fortalecer o ciclo da Reforma Agrária que já está quase se instalando em nosso país, é fato que Ribeirão Preto seria o primeiro grande beneficiado, já que Comércio e Indústria locais e regionais se beneficiam com essa integração de centenas de famílias até agora mantidas à margem da produção responsável e do mercado urbano ${ }^{10}$.

Em outros textos do DN, notamos novamente a aproximação com os setores rurais, apoiando-se na Doutrina Social Cristã e o compromisso, enquanto ator social, na transformação e progresso da cidade. Percebemos que o jornal e seu diretor, Pe. Celso, antecipavam, de certa forma, o espírito de Puebla (1979) e mantinham uma linha ideológica progressista. Com a deflagração do golpe, o DN deixou de circular por cerca de dois meses e o Pe. Celso foi preso pela Polícia Política local. Depois disso, não se tem registros do religioso, mas sabe-se que ele acabou por abandonar a batina. Quanto ao jornal, passou a ser dirigido pelo Pe. Angélico Sândalo Bernardino, que mantinha aproximações com a ideologia da direção anterior, porém, de maneira menos enfática.

\section{Considerações Finais}

A História local, também chamada de micro história, nos permite compreender de forma aprofundada as relações sociais existentes em um espaço delimitado, porém complexo, que se faz presente em âmbitos nacionais. Compreende-se que o regional está inserido na lógica do nacional e, por isso, é necessário entender como se dava esse 9 SEM AUTOR. Libertemos a Roça. Diánio de Notícias. Coluna Nosso Comentário. Ribeirão Preto. 08 de novembro de 1963.

10ldem, ibidem. 
ambiente, demonstrar suas singularidades e deixar claro que a sociedade é heterogênea e dinâmica.

No caso das práticas jornalísticas, nos deparamos com o estudo de um tipo de produção empresarial voltada aos desejos da comunidade, mas que ao mesmo tempo, seguia uma lógica de produção da grande imprensa. Isso de modo a criar uma identificação com o público e, também, manter um diálogo com a sociedade do espaço em que está inserido. Estudamos o "Diário de Notícias", matutino local ribeirão-pretano, mantido pela Igreja Católica, em um período conturbado da História Nacional. O DN lutava em nome da justiça social, sendo notáveis as campanhas em prol das reformas estruturais de base, em especial, a agrária, e a participação ativa do movimento sindical "Frente Agrária Paulista", que defendia os direitos dos trabalhadores rurais e a emancipação do campo. O que vemos é um jornal engajado em causas sociais e políticas, correspondendo às práticas de outros diários católicos nacionais e evidenciando o caráter comunitário e cidadão do jornalismo de interior.

A particularização e a significação do jornalismo local o fazem uma referência, pois cada vez mais, caminhamos para um jornalismo personalizado e localizado, que atendam aos nossos interesses e discutam as especificidades locais. Por isso, faz-se necessário ampliar as discussões sobre jornalismo local e História, a fim de entender os processos produtivos que nos levam as modelos atuais de configuração das empresas de notícias.

\section{Referências}

ARAÚJO, L. C. E. de. \& GERALDO, S. Memória do Jornalismo Impresso de Ribeirão Preto - O início da profissionalização das redações (1965-82). XI Simpósio de Ciências da Comunicação na Região Sudeste/INTERCOM. Ribeirão Preto, 2006.

BARROS, J. D. "Micro-História". In: O Campo da História. Petrópolis: Editora Vozes, 2011, p.152-179.

BELTRÃO, L. O jornalismo interiorano a serviço das comunidades. In: ASSIS, F. (Org). Imprensa do interior: conceitos e contextos. Chapecó: Argos, 2013.

CAMPONEZ, C. Jornalismo de Proximidade. Coimbra: Minerva Coimbra, 2002.

COLUSSI, J. Jornalismo regional e construção da cidadania: 0 caso da Folha da Região de Araçatuba. Dissertação (Mestrado, mestrado em comunicação) FAAC- Bauru, 2005. 
DORNELLES, B. Imprensa local. In: Documentos básicos - Mídia Cidadã. Seminário WACC/UNESP/METODISTA. São Bernardo do Campo. 28 a 30 de novembro de 2005.

LOPES, D. F.; COELHO SOBRINHO, J.; PROENÇA, J. L. (Orgs). A evolução do jornalismo em São Paulo. São Paulo: Edicon: ECA/USP, 1998.

MARINO, D. Orquídeas para Lincoln Gordon: depoimentos sobre o golpe de 64 . Ribeirão Preto: Legis Summa, 1998.

MORIN, E. Educação e complexidade, os sete saberes e outros ensaios. São Paulo: Cortez, 2005.

PAULINO, C. L. T. Tempos de resistência.Ribeirão Preto: Editora Oswaldo Cruz Empreendimentos Ltda., 2012.

RIBEIRO, A. P. G. Imprensa e História no Rio de Janeiro dos anos 1950. Rio de Janeiro: e-papers, 2007.

SANT'ANA. A. M. Imprensa, Educação e Sociedade no interior paulista: Ribeirão Preto (1948-1959). Dissertação (Mestrado em Educação Escolar), UNESP, Araraquara, 2010.

THOMPSON, J. B. Ideologia e cultura moderna: teoria social e crítica na era dos meios de comunicação de massa. Petrópolis: Vozes, 2000.

TOLEDO, C. N. O governo Goulart e o golpe de 64. São Paulo: Brasiliense, 2004.

Campinas: Unicamp, 1997.

1964: Visões críticas do golpe: Democracia e reformas no populismo.

VICENTE, M. M. História e comunicação na ordem internacional. São Paulo: Cultura Acadêmica, 2009.

WEFFORT, F. O populismo na política brasileira. Rio de Janeiro: Paz e Terra, 1978.

Recebido em: 07/10/2017

Publicado em: 01/12/2017 